УДК $82-1$

\title{
А.Ю. Незнамова
}

\section{ЭЛЕМЕНТЫ ПОЭТИКИ КОМЕДИИ ДЕЛЬ АРТЕ В «ПОЭМЕ БЕЗ ГЕРОЯ» А. АХМАТОВОЙ}

\begin{abstract}
Анализируются реминисценции поэтики итальянской комедии дель арте XVIII в. в «Поэме без героя» А.А. Ахматовой, присутствующие не только на мотивно-тематическом уровне, но и на уровне конструктивных принципов поэмы. Цель настоящей статьи - показать, что поэтика комедии дель арте является одним из структурно-смысловых элементов поэмы, хотя и воспринята опосредованно - через традицию и эстетику маскарада. Рассматриваются вопрос о соотношении жанровых источников поэмы, система персонажей, семантическое наполнение понятий «арлекинада», «гофманиана», «карнавал», «маскарад».

Ключевые слова: А.А. Ахматова; «Поэма без героя»; комедия дель арте; Серебряный век; театр; маскарад.
\end{abstract}

Посвящается П. В. М.

Надо обладать большой смелостью, чтобы в 41 году писать об Арлекинах, Коломбинах и Пьеро

Марина Цветаева [1. С. 658]

Италия в сознании русских поэтов - это не только реальная страна, но и образ иной культуры. Комедия дель арте - одна из несомненных составляющих общего представления не только русской, но и мировой культуры о высших достижениях творческого гения итальянского народа и итальянской словесности (в том случае, когда речь идет о текстах «сценариев» комедии дель арте).

Демократичность и зрелищность комедии дель арте, ее синтетический характер, веселая беспечность атмосферы спектакля, возможность импровизации и самовыражения актера ${ }^{1}$, неудержимый полет фантазии не могли не привлекать к ней внимание всей Европы на протяжении XVII-XVIII вв. и позднее, когда сама комедия дель арте уже прекратила свое существование.

Родиной комедии дель арте считается Венеция. Венецианский текст в русской литературе актуализируется с особенной интенсивностью в начале XX в.; на рубеже веков Венеция стала восприниматься преимущественно как призрачный топос [2. С. 40]. Соответственно, начало ХХ в. отмечено и взлетом интереса к комедии дель арте - тоже до некоторой степени призрачного и обманчивого жанра в силу его масочности и импровизационности, которая оставила в текстовых свидетельствах его исторического существования только бледные следы ${ }^{2}$.

В этот период в России наступает расцвет театрального искусства. Присущие эпохе эстетические искания руководствуются идей взаимопроникновения искусств, недаром артистические кружки начала века объединяют в своем составе писателей, художников, музыкантов и актеров. Общее настроение эпохи, точнее, рубежа эпох, ознаменовано увлеченностью мистицизмом, профетическими и эсхатологическими настроениями. Поэтому тема (и шире - концепт) маскарада - одна из самых распространенных в эту эпоху - получает различные трактовки: маскарад воспринимается не только как карнавальное веселье, но и как обман, искусство, мистика и даже как dance macabre. Понятие маски соотносится с функциями личины, лицедейства. Это как нельзя более подходит к эпохе Серебряного века, характеризовавшейся мно- гообразными жизнетворческими экспериментами. Деятели русской культуры подчиняли свое бытовое поведение выбранной маске или амплуа, желая, чтобы публика видела не столько их реальные лица, сколько созданные ими самими образы их реальных лиц.

В 1917 г. В.Э. Мейерхольдом был поставлен спектакль по драме М.Ю. Лермонтова «Маскарад» (сценография А.Я. Головина). На генеральной репетиции присутствовали многие «действующие лица» поэмы: А. Ахматова, Б. Анреп, О.А. Глебова-Судейкина, А.А. Блок, М. Кузмин и др. Действие охватывало и зрительный зал. В декорации были использованы зеркала, а на сцене действовали венецианские маски: Пьеро и Неизвестный в костюме бауты [3. Ч. 1]. Тема маскарада является общей для произведений Лермонтова и Ахматовой, отчасти соотносим и сюжет: в основе действия обоих произведений - любовный треугольник, отношения в котором заканчиваются трагически: смертью одного из участников.

Строки «Поэмы без героя» «Мейерхольдовы арапчата // Затевают опять возню» [1. С. 397], создающие ощущение инфернальной игры адских сил (чернолицые арапчата вполне способны вызвать ассоциацию с бесенятами), на самом деле лишь иллюстрируют особый сценический прием - использование слуг (это могли быть арапчата или «дзанни» итальянской комедии дель арте) для перестановки декораций на сцене прямо на глазах у зрителя.

В толпе ряженых наряду с персонажами, воплощающими «вечные» образы, возникает режиссер спектакля под маской Доктора Дапертутто. Трансформация реальности приемом двойничества человека и его тени-маски (ср. псевдоним В.Э. Мейерхольда $^{3}$ ) имеет аналогии в поэме А. Ахматовой, для которой поэтика двойничества и зеркальности является одним из характерных творческих приемов [3. Ч. 3].

Следует заметить, что комедия дель арте не является единственной жанровой традицией в реализации карнавальной темы. Поэтика и семантика карнавала определены не только его античным (древнеримским, т.е. протоитальянским) генезисом, но и европейской средневековой традицией (в особенности французской). Кроме того, в поэме Ахматовой нередко возни- 
кают мотивы шабаша ведьм как ассоциативная отсылка к гетевскому «Фаусту», где мотив карнавала преломляется весьма своеобразно. Таким образом, комедия дель арте, жанр изначально развлекательный, у Ахматовой обретает инфернально-трагическое наполнение («адская арлекинада»), и актерское перевоплощение может иметь семантику не смены личины, а ведьминского превращения, смены сущности. Жанровой основой послужила романтическая поэма, о чем прямо говорит автор:

\section{А столетняя чаровнииа \\ Вдруг проснулась и веселиться \\ Захотела. Я ни при чем. \\ Кружевной роняет платочек, Томно жмурится из-за строчек И брюлловским манит плечом}

[1. C. 410].

Таким образом, создается целый комплекс разнообразных эстетик, принадлежащих разным родам искусства, которые накладываются и влияют одна на другую - своего рода аналогия полилингвальности комедии дель арте, пользующейся разными диалектами итальянского языка.

Романтическая поэтика Ахматовой очевидна в использовании автором жанровой модели баллады, о чем свидетельствуют основные сюжетные мотивы поэмы (самоубийство, потусторонние явления), цитаты и эпиграфы к главам (из собственной «Новогодней баллады», из баллады Жуковского «Светлана»), стремительное развитие действия, время действия.

Ахматова пишет о веренице гостей из прошлого, по сути, о мертвецах. Их призрачность и нереальность подчеркнуты именно их масочностью: маска - это не лицо, а личина, вполне мо́гущая прикрывать оскал черепа (ср. устойчивое выражение «маска смерти»). Свойственная романтическому двоемирию граница между мирами реальным и воображаемым, обыденным и маскарадным налицо, но она становится зыбкой, поскольку миры эти легко перетекают друг в друга («Только как же могло случиться, // Что одна я из них жива?» [Там же. С. 391]). Маскарад с потусторонним оттенком распространяется и на действительность, присутствие масок делает реальность ирреальной.

Мотив кукольности наряду с мотивом двойничества фигурирует в характеристике героини: «Что глядишь так смутно и зорко, // Петербургская кукла, актерка, // Ты - один из моих двойников» [Там же. С. 399]. Поэтому вполне логично - и по историко-культурной ассоциации с прошлым, и по смыслу создаваемого комбинированного реально-призрачно-массового мирообраза - в поэме возникает и маска Петрушки (ср. балет И. Стравинского «Петрушка», 1911 г., вторая редакция - 1948 г., содержащий сюжет «оживания» куклы), намечая проекцию сюжета в будущее.

В «Поэме без героя», посвященной десятым годам XX в., театральная тема связана с образом главной героини, актрисы Ольги Афанасьевны ГлебовойСудейкиной, история жизни и любви которой лежит в основе сюжета поэмы [4]. По признанию Ахматовой, изначально прототипами главной героини были и другие замечательные женщины эпохи: Т. Карсавина,
С. Андронникова, Т. Вечеслова [3. Ч. 3. Гл. 2]. Однако в конечном счете репрезентантом эпохи становится именно Глебова-Судейкина, на что указывает перифрастическая номинация героини «Коломбина десятых годов», свидетельствующая как об актуальности ассоциаций с комедией дель арте, так и об антропологизации эпохи через образ героини, который Ахматова сочла наиболее эквивалентным историческому времени $[6,7]$.

Роли Глебовой-Судейкиной, упомянутые в поэме, - Козлоногая, Путаница, Псиша (Психея) (две последние сливаются у Ахматовой в одну «ПутаницаПсихея»).

При изображении Козлоногой (это, пожалуй, вторая по важности для формирования образа героини роль в поэме, она проецируется на все содержание) соединены два эмблематичных анималистических образа: голубица, несущая семантику кротости, чистоты и невинности, принадлежащая небу, и коза, воплощающая порочность, сладострастие, принадлежность стихии карнавала, сфере животного «низа» ${ }^{4}$ :

А смиренница и красотка

Tbl, что пеструю пляшешь чечетку

Снова гулишь томно и кротко. «Que me veut mon Prince Carnaval?»

Все эти роли синтезирует образ Путаницы - это главный образ, в котором входит в поэму Ольга ГлебоваСудейкина. Он соотносится и с тематикой поэмы (маскарадностью), и с ее поэтикой: «зеркальностью» и «непонятностью». Путаница - «Душа водевиля», поэма Ахматовой - «перевернутый» водевиль, трагический. Впрочем, сама Ахматова всячески подчеркивала отсутствие родственности образов Путаницы в пьесе и в поэме: «Кстати, о Путанице. Все, что я знала о ней до вчерашнего дня (6 июня 1958 г.), было заглавие и портрет О.А. в этой роли, сделанный С. Судейкиным» [Там же. С. 420].

Героиня показана воплощенной в этих ролях не на сцене, а в жизни, между тем как отличительная особенность венецианского карнавала - это вживание актера в образ и жизнь в этом образе, усвоение основных характерологических черт. Маска становится вторым лицом актера, его своеобразным двойником, столь же живым, полноправно существующим, сколь и сам человек.

В артистической среде бытовое поведение не было чисто бытовым. Искусство привносилось в повседневную жизнь. Этот своего рода постоянный маскарад характерная черта эпохи. И только в посвящении, т.е. много лет спустя, главная героиня показана не «в маске», не в каком-либо художественном образе.

Образ реальной биографической героини порой все же «выглядывает» из-за примеряемых ею масок, но сейчас же происходит «ускользание» героини и вхождение ее в один из образов:

$$
\begin{aligned}
& T \text { в в Россию пришла ниоткуда, } \\
& \text { О мое белокурое чудо, } \\
& \text { Коломбина десятых годов <..> }
\end{aligned}
$$

[Там же. С. 399];

Вся в ияветах, как «Весна» Боттичелли $T$ bы друзей принимала в постели <..>

[Там же. С. 400]. 
Поэтика двойничества позволяет говорить о возможности преломления образа героини через образ автора.

В стихах Вс. Князева часто упоминется маска Пьеро $^{5}$ и очевидно самоотождествление с ней поэта; рядом возникает образ Коломбины, в то же время появляются черты «голубой героини» («палевый локон», «вы милая, нежная Коломбина, вся розовая в голубом»), что отсылает к эстетике комедии дель арте (образы «голубой героини» и «розового кавалера», протагонистической пары). Однако возможность такого сравнения сомнительна: здесь также налицо влияние французской версии карнавала (Пьеро вместо итальянского Педрилло, трансформация его образа и образа Коломбины) впрочем, французские карнавальные образы Пьеро, Коломбины и Арлекина генетически восходят именно к итальянской комедии дель арте.

Еще одна венецианская маска, упоминаемая в поэме - Арлекин. Не воплощенная в конкретном персонаже, она служит метафорой или толпы гостей-призраков, или атмосферы самого действия, или духа времени («Этой адской арлекинады // Издалека заслышав вой» [1. С. 406]). При этом актуализируется именно инфернальное значение маски, а не традиционная ипостась «второго дзанни», или глупого слуги, или усилившиеся поздние плутовские коннотации образа.

Существует большое количество работ, где рассматривается соотношение автора и героини, которое в основном определяется ахматовской цитатой «Ты один из моих двойников» [Там же. С. 399]. Собственно, двойничество тоже есть свойство поэтики комедии дель арте, но не является ее отличительным признаком, также наличествуя в романтизме, реализме и народном творчестве. Однако в комедии дель арте система двойников строго иерархична, что связано с двуплановостью сюжета (не предвестие ли это романтического двоемирия?). «Высокой» паре влюбленных - «голубой героине» и «розовому кавалеру» на «низком», профаном плане - соответствует пара слуг, помогающих им и устраивающих попутно свои собственные любовные дела ${ }^{6}$. Однако именно слуги, их проделки и трюки были двигателем сюжета, источником комизма и обеспечивали занимательность представления, выходя на первый план (ведь комедия дель арте была жанром демократическим), а пара влюбленных обеспечивала сюжету «чувствительность» и поэтичность, реализуя потребность зрителей в катарсисе.

Что же для Ахматовой стоит за понятием «маска»? Словоупотребления в поэме, связанные с семантикой маски, - маскарад, тени, ряженые, карнавал. Авторские определения: арлекинада (адская), гофманиана, «Петербургская чертовня».

В тексте поэмы упомянута баута. В примечаниях сказано: «маска с капюшоном». Не указана локальная отнесенность маски, ее сугубо венецианский характер неважен. Основное назначение капюшона - скрыть лицо. Именно эта маскирующая функция является особенно важной для маски у Ахматовой.

В маскараде, изначально имеющем также итальянские корни, иная семантика ношения маски по сравнению с комедией дель арте: не отождествление себя с амплуа, а сокрытие истинного лица и вольное поведение в связи с безнаказанностью. При своем возникновении маскарад имел ритуальные корни, будучи частью карнавала, но затем получил статус светского развлечения. Таким образом, в семантике маскарада дифференциальными становятся понятия «обман», «шутка». Можно утверждать, однако, что у Ахматовой сохраняются оба оттенка значений: так, с темой Дон Жуана (о чем свидетельствует эпиграф), так же как и с темой Фауста, связана тема возмездия, наказания за вседозволенность, что исключено в современном понимании маскарада. Эпиграф к первой главе первой части отсылает к раннему стихотворению Ахматовой «После ветра и мороза было...» (1914), которое содержит строки «Угадать нетрудно было вора // Я его узнала по глазам» [1. С. 68]. Допускается возможность двоякого прочтения, когда речь идет не только о психологизме, но и о маскараде, ведь при ношении маски у человека остаются открытыми именно глаза, что делает возможным узнавание ряженого. Кроме того, наименование «вор» соответствует семантике «совершение неблаговидного поступка под прикрытием маски».

Тема ряженых связана и с русской национальной традицией. Ряженье наиболее характерно для рождественского поста и особенно святок, что совпадает с указанными в поэме датами: 5 января (le jour des rois и «крещенский вечерок»). В отличие от карнавала, ряженье сопровождалось колядками и просьбами и имело сакральный смысл, а именно установление связи между двумя мирами (ср. представления о приходе душ умерших с того света на землю, о разгуле нечистой силы в середине зимы).

Здесь возникает сходство с сюжетом Дон Жуана, к которому возмездие пришло в виде ожившей статуи. Кроме этого «оживления», оживает изображение на полотне, оживает и сама поэма. Жанровая форма превращается в женщину. Создание поэмы - магическое действо, оживление предметов и призраков, всплывающих в сознании автора, чтобы затем вновь умереть: таким образом, в поэме происходит своеобразный ритуальный обряд. Во вступлении Ахматова говорит: «Как будто прощаюсь снова // С тем, с чем давно простилась, // Как будто перекрестилась // И под темные своды схожу» [1. С. 388]. Написанное в осажденном Ленинграде ${ }^{7}$ вступление звучит поистине трагически.

Еще одно определение маскарада в поэме: «Праздник мертвой листвы» [Там же. С. 391] (ср: «Новогодний праздник длился пышно...» [Там же. С. 68]). Праздник сам по себе не имеет к листве никакого отношения (такое сочетание - своего рода оксюморон), следовательно, метафора преющей листвы появляется по отношению к происходящему в поэме, к диалектике развития времени. Значит, словом «праздник» (синонимы - карнавал, маскарад) обозначено именно действо в поэме.

Что же напрямую указывает на связь ахматовских масок с венецианской комедией дель арте? Очевидно, это прежде всего строки «Вы ошиблись: Венеция дожей - // Это рядом...» [1. С. 390]. Однако это не современная Венеция - дожи, как и комедия дель арте, отошли в прошлое. Но авторская ремарка указывает на 
то, что это топос-призрак, так же как и тени, появившейся из прошлого, чтобы затем вновь исчезнуть.

Еще одна черта комедии дель арте - импровизационность. Был заранее известен лишь общий сценарий действия, остальное (реплики, трюки) принадлежало области творчества и импровизаторского дара актера. Демократический характер комедии диктовал возможность взаимодействия актеров и зрителей, вовлечение последних в представление.

В поэме действие (особенно это касается сцен с участием масок) развивается скачкообразно и обладает непредсказуемостью, поминутно ставя в замешательство автора, выступающего в роли как-бы-зрителя ${ }^{8}$. Непредсказуемо их появление (это подчеркивает авторская сноска «Три $к$ выражают замешательство автоpa» [1. С. 391]), так же как и их исчезновение: «Что ж вы все убегаете вместе...» [Там же. С. 393].

Общение с масками характеризуется спонтанностью («Вас я вздумала нынче прославить...» [Там же. С. 390], хотя до этого автор ждет других гостей; появление масок, их уход) и их автономностью относительно воли автора (непослушание). Таким образом, автор здесь предстает не как режиссер произведения, но как зритель спонтанного действа, не зависящего от его воли.

Паратекст заслуживает особого внимания как своего рода авторская интермедия к основному действию поэмы. Ремарки способствуют восприятию текста как театрального действия, разворачивающегося на сцене. Сноски и примечания, принадлежащие автору, носят в некоторой степени пародийный характер («до смешного правдивые», по выражению Ахматовой).

Во второй части «Решка» действие происходит в 1941 г. Мотивы маскарада появляются и здесь, но все направлено на его (маскарада) отрицание и дискредитацию (не оттого ли заглавие «Решка»?).

Ремарка содержит характеристику 1913 г.: «Только что пронеслась адская арлекинада 13 года, разбудив безмолвие великой молчальницы-эпохи и оставив за собой тот свойственный каждому праздничному или похоронному шествию беспорядок - дым факелов, цветы на полу, навсегда потерянные священные сувениры» [1. С. 405]. Осознание «беспорядка» как последствия маскарадного празднества становится характеристикой эпохи. По этому поводу Алла Демидова заметила: «Я думаю, это не собственная вина Ахматовой, а ее двойника, ее лирического героя, скорее даже ее поколения, жившего так беспечно в предгрозовые годы <..> двойничество выявило очень важную для Ахматовой нравственную тему. Она и ее современники не удержали новый век на должной нравственной и духовной высоте - и поплатились за это вместе со всей страной теми испытаниями, которые начались с Первой мировой войной и революцией 1917 года» [3. Ч. 4. Гл. 2]. Именно поэтому в третью главу входит широкий исторический контекст. Возможно, это и составляет главный пафос поэмы.

О соотношении времен - прошлого и настоящего говорится в строках:

Между «помнить» и «вспомнить», други

Расстояние как от Луги

До страны атласных баут

[1. C. 408].
По свидетельствам современников, баута - не только символ карнавала, но и вполне конкретная деталь интерьера в «Привале комедиантов», рядом с портретом Ольги Глебовой-Судейкиной.

Противопоставляя времена, Ахматова пишет: Карнавальной полночью римской
И не пахнет

Отрицание наличия хоть какой-то частицы Италии в современной жизни наводит на воспоминание о традиции итальянского текста в русской культуре: восторженного отношения к Италии в период его формирования - в начале XIX в., разочарования - в середине и второй его половине. Двадцатый век в полной мере повторил эту тенденцию. Легкомысленное увлечение Серебряного века Италией и итальянским карнавалом несовременно и вызывает осуждение. Автор в этой части словно бы оправдывается перед читателями:

И сама я была не рада,
Этой адской арлекинады
Издалека засльшав вой

[Там же. С. 406];

или:
А столетняя чаровница
Вдруг очнулась и веселиться
Захотела. Я ни при чем

[Там же. С. 410].

Неожиданно сравнивается с маской Седьмая симфония Шостаковича, ставшая одним из культурных «символов» блокады:
И со мною моя «Седьмая»
Полумертвая и немая,
Рот ее сведен и открыт,
Словно рот трагической маски,
Но он черной замазан краской
И сухою землей набит

[Там же. С. 407].

Сороковые годы - эпоха настоящих, «некукольных» страданий, когда умирают даже произведения искусства. Как контрапункт к «арлекинаде» появляются, усиливаясь к финалу, мотивы античной трагедии:

Пятым актом из Летнего Сада

Пахнет...

[Там же. С. 398];

Я же роль рокового хора

На себя согласна принять

[Там же];

Скоро мне нужна будет лира,

Но Софокла уже, не Шекспира

На пороге стоит Судьба

[Там же. С. 408].

Если первые две приведенные цитаты еще можно отнести на счет героев поэмы, то третья явно говорит о самоотождествлении автора с трагиками Античности и Возрождения. Подлинная трагедия - не любовный треугольник Арлекина, Коломбины и Пьеро, а грядущая история. Автор, надевающий маску античного трагика (показательна игра созвучий «рок хор»), - это, вероятно, не столько видение Ахматовой самой себя, сколько сознание, поднявшееся над временем и понявшее значение будущих катастроф. 


\section{ПРИМЕЧАНИЯ}



\section{ЛИТЕРАТУРА}

1. Ахматова А. Стихотворения и поэмы. М., 2009.

2. Цивьян Т.В. «Золотая голубятня у воды...»: Венеция Ахматовой на фоне других русских Венеций // Семиотические путешествия. СПб., 2001. С. 40-50.

3. Демидова А. Ахматовские зеркала. Ч. 1-5. URL: http://www.akhmatova.org/bio/demidova3.htm

4. Чуковская Л.К. Герой «Поэмы без героя» // Знамя. 2004. № 9. С. 128-141.

5. Лебедева О.Б. Традиции commedia dell'arte в лирике и драме Александра Блока // Имагология и компаративистика. 2014 . № 1. С. $145-164$.

6. Тименчик Р.Д. Заметки о «Поэме без героя» // Поэма без героя : в 5 кн. / вступ. ст. Р.Д. Тименчика. М. : Изд-во МПИ, 1989. С. 3-25.

7. Тименчик Р.Д. Рижский эпизод в «Поэме без героя» Анны Ахматовой // Даугава. 1984. № 2. С. $113-121$.

Статья представлена научной редакцией «Филология» 8 февраля 2016 г.

\section{ELEMENTS OF COMMEDIA DELL'ARTE POETICS IN POEM WITHOUT A HERO BY ANNA AKHMATOVA}

Tomsk State University Journal, 2016, 403, 10-14. DOI: 10.17223/15617793/403/2

Neznamova Anna Yu. Tomsk State University (Tomsk, Russian Federation). E-mail: paradoxoid@inbox.ru

Keywords: Akhmatova; Poem Without a Hero; commedia dell'arte; 20th century; theater; masquerade.

The article tells about the problem of using elements of poetics of Italian commedia dell'arte (13th century), a specifically Italian phenomenon of a universal cultural importance, in Poema bez geroia [Poem Without A Hero] by A. Akhmatova. During the first decade of the 20th century the theater flourishes in Russia. The common climate of the era (or, rather, the turn of the era) is marked by an avocation to the spirit of mysticism, prophecy and eschatology. The theme of masquerade is one of the most common in this period. Therefore, masquerade has different interpretations, it is not only the carnival fun, but also deception, art, mysticism, even dance macabre. The concept of the mask corresponds to the concept of magnitude, hypocrisy. It most suited the Silver Age characterized by numerous life-building experiments. Russian artists submitted their everyday behavior to a mask or a role they selected wanting the audience to see the image of their real faces they created themselves rather than their real faces. It should be noted that commedia dell'arte is not the only genre tradition in the implementation of the carnival theme. Poetics and semantics of the carnival are determined not only by its antique (of the ancient Rome, thus proto-Italian) origin, but also by the European Medieval (especially French) tradition. In addition, there are motifs of the coven that refer to Goethe's Faust. Thus, commedia dell'arte, originally an entertaining genre, acquires tragic and infernal nature ("infernal harlequinade") in Akhmatova's work, where actor's dramatic identification may have the semantics of witch metamorphosis, change of the essence, not of change of masks. In Poem Without a Hero, dedicated to the 1910s, the theatrical theme is associated with the image of the protagonist, Olga Glebova-Sudeykina, whose life and love story is the basis of the poem. However, the main character represents the epoch, as indicated by her nomination "Colombine of the '10s". The multidimensional image of the character which consists of the "top" and the "bottom" carnival elements is described using the motif of the doll, provoking the reader to ethically evaluate the "carnival" of the $1910 \mathrm{~s}$ and of its participants. The love triangle is a traditional story interpreted through figures of commedia dell'arte. In the story, there are several levels, the line of the heroine is projected on the storyline of the author. This theme of duality and mirror is also in the artistic code of commedia dell'arte. In this article, the author concludes that poetics of commedia dell'arte is one of the structural and semantic elements of the poem, although it was be perceived via the tradition and the esthetics of masquerade.

\section{REFERENCES}

1. Akhmatova, A. (2009) Stikhotvoreniya i poemy [Poetry and poems]. Moscow: PROZAiK.

2. Tsiv'yan, T.V. (2001) Semioticheskie puteshestviya [Semiotic travel]. St. Petersburg: Izd-vo Ivana Limbakha. pp. 40-50.

3. Demidova, A. (2010) Akhmatovskie zerkala [Akhmatova's mirrors]. Parts 1-5. [Online]. Available from: http://www.akhmatova.org/bio/demidova3.htm

4. Chukovskaya, L.K. (2004) Geroy "Poemy bez geroya" [Hero of the Poem Without a Hero]. Znamya. 9. pp. 128-141.

5. Lebedeva, O.B. (2014) The traditions of commedia dell'arte in Alexander Blok's lyric and drama ("Verses about the Beautiful Lady" - "The Fairground Booth" - "Mask of snow"). Imagologiya i komparativistika - Imagology and Comparative Studies. pp. 145-164. (In Russian).

6. Timenchik, R.D. (1989) Zametki o "Poeme bez geroya" [Notes on the Poem Without a Hero]. In: Akhmatova, A. Poema bez geroya: V 5 kn. [Poem Without a Hero: in 5 books]. Moscow: Izd-vo MPI.

7. Timenchik, R.D. (1984) Rizhskiy epizod v "Poeme bez geroya" Anny Akhmatovoy [The Riga episode in the Poem Without a Hero by A. Akhmatova]. Daugava. 2. pp. 113-121. 